Published in final edited form as:

J Crohns Colitis. 2014 February ; 8(2): 113-119. doi:10.1016/j.crohns.2013.07.002.

\title{
Risk Factors for Depression in the Elderly Inflammatory Bowel Disease Population
}

\author{
Millie D. Long, MD, MPH ${ }^{1,2}$, Michael D. Kappelman, MD, MPH ${ }^{2,3}$, Christopher F. Martin, \\ MSPH $^{1,2}$, Wenli Chen, MS, MA ${ }^{2}$, Kristen Anton, $\mathbf{M S}^{2,4}$, and Robert S. Sandler, MD, MPH ${ }^{1,2}$ \\ 1 University of North Carolina at Chapel Hill, Department of Medicine, Division of \\ Gastroenterology and Hepatology \\ ${ }^{2}$ Center for Gastrointestinal Biology and Disease, Chapel Hill, NC \\ ${ }^{3}$ University of North Carolina at Chapel Hill, Department of Pediatrics, Division of \\ Gastroenterology and Hepatology \\ ${ }^{4}$ Geisel School of Medicine at Dartmouth
}

\begin{abstract}
Background and Aims-Little is known about depression in elderly individuals with inflammatory bowel diseases (IBD). We assessed the point prevalence of depression and determined associations with disease activity, quality of life, and medication adherence in elderly patients with IBD.
\end{abstract}

Methods-We identified elderly ( $₫ 65$ years) individuals within Crohn's and Colitis Foundation of America Partners, an online IBD cohort. Individuals completed the short- geriatric depression scale (GDS). We used bivariate statistics to determine whether demographic or disease-related factors, disease activity, quality of life or medication adherence was associated with depression. We used logistic regression to estimate independent effects of depression on medication adherence.

Results-A total of 359 elderly individuals with IBD completed the GDS. The mean age was 70.2 years (sd 4.7); mean disease duration was 25.6 years (sd 17.6), 62.6\% had Crohn's disease (CD). The point prevalence of depression was $22.6 \%$. Lower education levels $(\mathrm{p}=0.001)$, higher corticosteroid use $(<0.01)$ and lower exercise levels $(<0.001)$ were associated with depression. For

Corresponding Author: Millie D. Long MD, MPH, Campus Box 7080, University of North Carolina at Chapel Hill, Chapel Hill, NC 27599-7080, millie_long@med.unc.edu, Phone: 919-843-5795, Fax: 919-966-6842.

Author contribution: All authors have made substantial contributions to this work. MDL participated in all of the following: (1) the conception and design of the study, acquisition of data, analysis and interpretation of data, (2) drafting the article or revising it critically for important intellectual content, (3) final approval of the version to be submitted. MDK participated in 1) the conception and design of the study, (2) final approval of the version to be submitted. CFM participated in 1) the conception and design of the study, acquisition of data, analysis and 2) final approval of the version to be submitted. WC participated in 1) acquisition of data, 2) final approval of the version to be submitted. KS participated in 1) acquisition of data ,2) final approval of the version to be submitted. RSS participated in 1) the conception and design of the study, (2) final approval of the version to be submitted.

Conference presentation: This work was presented as a poster at the American College of Gastroenterology meeting, October 2012.

We certify that this manuscript, including related data, figures and tables has not been previously published and the manuscript is not under consideration elsewhere.

The authors have no financial disclosures relevant to this work. Dr. Long has previously served as consultant to UCB, Inc. 
both CD and ulcerative colitis (UC), those with depression had increased disease activity (short Crohn's disease activity index 52.5 versus $29, \mathrm{p}=0.005$, and simple clinical colitis activity index 5 versus $2, \mathrm{p}=0.003$ ). Depressed patients had lower quality of life (short IBD questionnaire 4.6 versus 5.7, $\mathrm{p}<0.001$ ). Depressed individuals had reduced medication adherence (adjusted OR 2.18; 95\% CI 1.04-4.57).

Conclusions-Depression is common in this geriatric IBD cohort. Depression is independently associated with reduced medication adherence. Recognition and treatment of depression in elderly patients with IBD could improve outcomes.

\section{Introduction}

Developed countries, such as the United States, with low birth rates and low mortality have contributed to an overall aging of the population. ${ }^{1}$ This aging population has a significant impact on costs of health care delivery. ${ }^{2}$ It is therefore important to understand and optimize health care delivery to the elderly; particularly among those with chronic diseases.

Depression is highly prevalent among individuals with chronic diseases. Importantly, depression can adversely affect the course and outcome of common chronic conditions. Therefore, improved recognition and treatment of depression in the elderly chronic disease population could improve outcomes.

Depression is a major health problem in the United States (US), with 1 in 10 adults meeting criteria for current depression. ${ }^{3}$ Risk factors for depression in chronic disease populations have included measures of poor health, female gender, lack of social support and levels of physical activity. ${ }^{4}$ An estimated $8.3 \%$ of diabetics, for example, meet criteria for major depression. ${ }^{5}$ Unfortunately, among diabetics, a significant proportion of individuals with depression are undiagnosed (as many as $45 \%$ of diabetics with depression remain undiagnosed). ${ }^{4}$ Depression can be both costly and debilitating.

Individuals with inflammatory bowel diseases (IBD) are one chronic disease population at increased risk for depression. Among IBD patients in Canada, the period prevalence of depression has been estimated to be triple that of the general population (16.3\% versus $5.6 \%) .{ }^{6}$ Risk factors for depression in the IBD population include female gender, lack of a partner, younger age, increased pain, and functional limitations. ${ }^{6}$ Fewer data are available about depression specifically in the elderly IBD population. There are well-described differences in depression rates and characteristics amongst the elderly general population. Risk factors for incident depression in the elderly general population include older age, personal history of depression, death of a spouse, health related factors and comorbid anxiety. ${ }^{7}$ In fact, in older age groups, psychoeducational and psychological interventions designed to increase protective factors have been shown to reduce incident depression by 20-25\% over 1-2 years in the general population. ${ }^{8}$ Such interventions could be implemented in an IBD population if depression were found to be prevalent.

We chose to focus on the elderly within this study due to the following factors: high rates of depression found in this segment of the general population without data in IBD, differing risk factors for depression in the elderly general population, and the potential for underrecognition and under-treatment of this problem in the IBD community. As depression in the 
elderly can be both preventable and treatable, with significant benefits on quality of life, we aimed to 1) assess the point prevalence of depression in an elderly cohort of patients with IBD using a readily available screening tool, 2) assess factors associated with depression in the elderly IBD population and 3) determine whether depression is associated with disease activity, quality of life, or medication adherence in this age group.

\section{Materials and Methods}

We identified elderly patients with IBD ( $\geq 65$ years old) who were enrolled in Crohn's and Colitis Foundation of America (CCFA) Partners, an internet-based cohort of individuals living with IBD. The cohort construction and characteristics have been described elsewhere. ${ }^{9}$ In brief, using multiple means of recruitment, over 12,000 individuals with selfreported IBD have enrolled in this online cohort registry since initiation. Cohort members are followed up every 6 months. Follow up includes a core survey with information on disease phenotype, disease activity, medications, and various patient reported outcomes (PROs). When possible, validated instruments for self report are used: the short Crohn's disease activity index (SCDAI), ${ }^{10}$ the simple clinical colitis activity index (SCCAI), ${ }^{11}$ the Manitoba IBD index (MIBDI) ${ }^{12}$ the short IBD questionnaire (SIBDQ), ${ }^{13}$ Morisky Medication Adherence Scale (MMAS) ${ }^{14}$ and Godin Leisure time index. ${ }^{15}$ There is also the opportunity for optional "modules" at 6 month intervals to assess specific components of living with IBD, such as depression.

In this study, we invited elderly individuals $\geq 65$ years of age enrolled in CCFA Partners cohort to complete the short form of the geriatric depression scale (GDS $)^{16}$ at the time of their planned 6 month-follow up interval ( 6 months after initial entry into the cohort). This module includes 15 yes/no questions and takes less than 10 minutes to complete (Figure 1). A score of $\geq 5$ on this scale suggests depression (specifically depressive risk warranting further evaluation). Scores up to 8 are considered consistent with mild depression; scores of 9-11 are consistent with moderate depresson and scores of 12-15 are consistent with severe depression. The long and short versions of this scale have been previously validated against research diagnostic criteria, billing measures (international classification of diseases, $10^{\text {th }}$ revision, ICD-10) and the diagnosis of depression within the diagnostic and statistical manual of mental disorders, 4 th edition (DSM-IV). ${ }^{16,17}$

\section{Data Collection and Management}

The data were collected entirely in a Web-based format, allowing for real-time implementation of range and consistency checks. The details of the data management system for CCFA Partners have been previously reported. ${ }^{9}$ The Web forms were accessible from any machine running a modern Internet browser with an active connection to the Internet; no special software was required.

\section{Statistical Analysis}

Descriptive statistics were used to characterize the population, including proportions and 95\% confidence intervals, medians and interquartile ranges, means and standard deviations (SD) as appropriate. Bivariate statistics were used to compare depression by IBD subtype 
(Crohn's disease (CD) versus ulcerative colitis (UC)) and by other risk factors. These statistics included Pearson's chi-square test statistic, Fisher's exact, Wilcoxon rank sum, and Student's t-test as appropriate. Logistic regression modeling was used to evaluate the independent effects of depression on medication adherence. STATA version 10.0 (College Station, TX) was used for all analyses and $\mathrm{P}<0.05$ was considered statistically significant. The study protocol was approved by the Institutional Review Board at the University of North Carolina at Chapel Hill.

\section{Results}

At the time of this study, 437 individuals were enrolled in CCFA Partners who were greater than 64 years of age and eligible for participation. A total of 361 initiated and 359 elderly individuals completed the short GDS module (82.2\%). Of these, 81 (22.6\%) met the cut-off on the depressive severity screen consistent with a diagnosis of major depression (GDS $\geq 5$ ). A total of $52(14.5 \%)$ had scores consistent with mild depression, 13 (3.6\%) had scores consistent with moderate depression and $16(4.5 \%)$ had scores consistent with severe depression. The mean age was 70.2 years (sd 4.7), with a mean disease duration of 25.6 years (sd 17.6). Approximately $2 / 3$ of the individuals had CD and $1 / 3$ had UC. The characteristics of the population by depression status are shown in table 1 . The point prevalence of depression did not differ by CD or UC status $(24.1 \%$ v. $20.2 \%, \mathrm{p}=0.39)$. Those with depression, as compared to no depression, also did not differ by age, gender, or disease duration. Significantly fewer IBD patients with depression had a college education $(\mathrm{p}=0.001)$. A significantly higher percentage of IBD patients with depression were on corticosteroids $(\mathrm{p}<0.01)$, with no difference for other classes of medications. Depressed patients also had significantly reduced exercise levels, as measured by the Godin score (15 (IQR 9-30) for depressed patients and 21 (IQR 9-37) for non-depressed patients, $\mathrm{p}<0.001$ ).

A total of 331 individuals had measured disease activity indices for CD or UC (sCDAI or SCCAI) and 355 completed the one question MIBDI on disease activity. Lacking a sCDAI or SCCAI was not significantly associated with depression. Characteristics of those missing sCDAI or SCCAI were similar in general, although $93 \%$ of those missing this information had CD. Those with depression reported significantly higher levels of disease activity for both CD and UC when measured by SCDAI and SCCAI, or by the MIBDI for the overall population (Figure 2a, 2b, 2c). Measures of quality of life were also reduced in depressed patients (SIBDQ 4.6 versus 5.7, $\mathrm{p}<0.001$ ). A total of 240 individuals were taking at least one medication for IBD and completed the MMAS. Those with depression reported significantly worse medication adherence when compared to those without depression (table 2).

In a logistic regression model, controlling for disease activity (MIBDI), education level, corticosteroid use and exercise, depression was significantly associated with reduced medication adherence (defined as MMAS score<8) (OR 2.18; 95\% CI 1.04-4.57).

\section{Discussion}

In this cross-sectional study, we found a relatively high point prevalence of depression (22.6\%) among elderly individuals with IBD in the CCFA Partners cohort. This is 
important, as depression is a potentially treatable disease and it is predicted to be one of the main causes of disability-adjusted life years by $2020 .{ }^{18}$ Reduction of depressive symptoms could impact disease management and quality of life in elderly individuals with IBD. Importantly, we also found that depression was associated with increased disease activity and reduced quality of life. Depression was independently associated with reduced medication adherence, which may be one mechanism of its significant impact on a chronic disease such as IBD. We chose to focus on the elderly in our study to determine if the point prevalence and risk factors differed from younger populations and due to the potential for under-recognition and under-treatment of this problem in the geriatric IBD community.

This point prevalence of depression we found in this study of individuals with IBD (22.6\%) is within the reported range of depression among elderly individuals in general (2-25\%). ${ }^{19-21}$ This range in the general population is quite broad, and is likely influenced by many factors such as setting (home versus nursing home), medical comorbidites and cognitive decline. In older adults, physical illness (such as IBD) is a well-established risk factor for depressive symptoms. The impact of physical illness on late-in-life depression is more striking than its role in younger adults. ${ }^{19,21}$

Depression has also been previously studied in the IBD population specifically. Using data from 2 large Canadian health surveys, Fuller-Thomson et al found approximately a 15\% prevalence of depression among those who reported CD or UC diagnoses for at least 6 months. This is triple the rate of depression found in the Canadian population. Risk factors for depression included female gender, those without partners, younger respondents, those who reported greater pain, and those who have functional limitations. ${ }^{6}$ Guthrie et al found a prevalence of anxiety and depression of $25.9 \%$ among a population of patients with $\mathrm{CD}$ and UC. They found that the prevalence of a psychological disorder contributed to poor health related quality of life, regardless of the disease severity. They also found no difference in depression and anxiety by $\mathrm{CD}$ as compared to UC. ${ }^{22}$

In a prospective study of depression and IBD, Mittermaier et al found a prevalence of depression (as measured by the Beck Depressive Index) of $28 \%$ at baseline. Depression at baseline was associated with increased numbers of relapses over the study period. ${ }^{23}$ In a French study of IBD patients, $11 \%$ were depressed and risk factors for depression included age, flares of disease, and socioeconomic factors. In a study of adolescents with IBD, 24.5\% met criteria for depression, with an association between disease symptoms and depression. ${ }^{24}$ The rates of depression reported in all of these studies are similar to those we found in our elderly population. Additionally, we also found no difference between CD and UC in rates of depression. However, these prior studies consisted primarily of younger patient populations.

We found interesting associations between and exercise, educational level and depression in this geriatric IBD population. The inverse association we found between exercise and depression is supported in the literature. For example, in chronic disease populations in general, those involved in exercise programs are less likely to report depressive symptoms. ${ }^{25}$ Moderate exercise has also been shown to be an effective treatment of depression, ${ }^{26}$ although particularly when used in combination with medications. ${ }^{27} \mathrm{We}$ also found an 
inverse association between education level and depression. These finding could potentially be explained by help-seeking behavior and related improvements in symptoms. Education level, in a complex model also including gender, health care utilization and the belief that depression is not a disease, has been associated with help-seeking behavior for depressive symptoms in community-dwelling older individuals. ${ }^{28}$ Regan et al also demonstrated a significant inverse association between education level and depressive symptoms in older adults. ${ }^{19}$

There have been several proposed mechanisms for the associations between depression and IBD. Patients with IBD are subject to the same risk factors for psychological distress as the general population (for example, childhood abuse). Medications could also play an important role in depression in IBD patients, as corticosteroids have been known to affect both mood and level of immunosuppression. This was true within our study, as those with depression were more likely to be on corticosteroids. Another mechanism through which depression could affect disease activity is through medication adherence. In a recent metaanalysis of depression and medication adherence among an adult population with chronic diseases, those who were depressed had 1.76 times the odds of being non-adherent as compared to a non-depressed patient. This meta-analysis included 31 studies and 18,245 participants with chronic diseases. ${ }^{29}$ It is also possible that IBD-related inflammation directly impacts severity of depression. Finally, there many other factors likely influencing rates of geriatric depression in IBD. Some examples of these factors may include ongoing allostatic load, poor disease course, development of dysplasia or cancer, other medical comorbidities and chronic pain.

There are several strengths to this study of depression in elderly patients with IBD. To our knowledge, we are the first to describe rates and risk factors for depression solely in an elderly population of individuals with IBD. We were also able to correlate depression with a validated scale of medication adherence in an elderly IBD population. Our hypothesis was that a principal mechanism through which depression could promote disease activity in this population would be through reduced adherence. Additionally, we were able to include a diverse population of elderly individuals in our study through the unique internet-based format. Prior studies of IBD have often been focused at tertiary care centers, whereas our study's catchment area includes anywhere with internet access.

There are also limitations to this study of depressive symptoms in elderly patients with IBD. As our study is cross-sectional, we were not able to determine whether depression or disease activity came first temporally. However, independent of causation, depression is known to affect quality of life (as seen in our population) and should be treated, if recognized. We also could not temporally correlate whether reductions in medication adherence came prior to increased disease activity. Another limitation to our study is that the CCFA Partners cohort is not population-based, and therefore may not be representative of the elderly population with IBD in the US. The non-representative sampling of the cohort makes it difficult to use these data to make inferences about the point prevalence of depression in the overall geriatric IBD population. However, the associations between depression and other factors in this study still maintain high internal reliability. We were missing data on SCDAI or SCCAI on 30 individuals, although we did have MIBDI on all but 5. Missing disease activity data 
was not associated with depression, therefore this was unlikely to influence the results. Additionally, CCFA Partners is a cohort based entirely upon self-reported disease and disease characteristics. It is possible that individuals may not report disease characteristics accurately. However, in a recent validation study within CCFA Partners, over 95\% of individuals accurately reported their disease type, confirmed by their treating physician (data not shown). There is also the potential for ascertainment bias in this study, both via how the patients were recruited and because of limitations of using a self-report instrument for the outcome. As internet capability is required to participate in the cohort, the population may be skewed towards a higher level of education or higher socioeconomic status. For this reason, we controlled for educational levels in our multivariable analysis. We could not account for cognitive impairment in the elderly within our analysis, although the internetbased modality of our survey does require a minimum level of cognitive abilities from our participants. The instrument that we used to assess depression was via self-report. This screening instrument has $92 \%$ sensitivity and $89 \%$ specificity for major depression evaluated against diagnostic criteria. However, the gold standard for a depression diagnosis is using a diagnostic interview by a mental health professional, which was not performed in our study. This instrument also does not assess suicidality. Finally, we did not have data on antidepressant use, so we therefore could not determine whether treatment of depression altered disease course.

In summary, we demonstrated the feasibility of a short tool to diagnose depression in elderly patients with IBD. We found that depression was common amongst this cohort of geriatric IBD patients. We also found that depression was associated with increased levels of disease activity and reductions in quality of life measurements. Other risk factors for depression in our cohort included educational level, corticosteroid use and exercise level. Finally, depression was independently associated with reduced medication adherence in the elderly IBD population. These findings could significantly impact the lives of elderly patients with IBD. Current pediatric guidelines recommend screening for depression in children with IBD. ${ }^{30}$ It may be reasonable to consider depression screening as part of routine care in geriatric IBD as well. Many treatments, including psychological counseling and interventions, have been shown to reduce depressive symptoms in older individuals. Recognition and treatment of depression in all age groups, including the geriatric IBD population, could improve quality of life and even disease-specific outcomes.

\section{Acknowledgments}

Grant support: This work was supported by a Career Development Award from the Crohn's and Colitis Foundation of America (MDL), NIH P30 DK34987 (RSS), and NIH 1K08DK088957-01 (MDK).

\section{References}

1. Rickards H, Prendergast M, Booth IW. Psychiatric presentation of Crohn's disease. Diagnostic delay and increased morbidity. Br J Psychiatry. 1994; 164:256-61. [PubMed: 8173832]

2. Sinha SK. Why the elderly could bankrupt Canada and how demographic imperatives will force the redesign of acute care service delivery. Healthc Pap. 2011; 11:46-51. discussion 86-91. [PubMed: 21464628]

3. Current depression among adults---United States, 2006 and 2008. MMWR Morb Mortal Wkly Rep. 2010; 59:1229-35. [PubMed: 20881934] 
4. Li C, Ford ES, Zhao G, Ahluwalia IB, Pearson WS, Mokdad AH. Prevalence and correlates of undiagnosed depression among U.S. adults with diabetes: the Behavioral Risk Factor Surveillance System, 2006. Diabetes Res Clin Pract. 2009; 83:268-79. [PubMed: 19111364]

5. Li C, Ford ES, Strine TW, Mokdad AH. Prevalence of depression among U.S. adults with diabetes: findings from the 2006 behavioral risk factor surveillance system. Diabetes Care. 2008; 31:105-7. [PubMed: 17934145]

6. Fuller-Thomson E, Sulman J. Depression and inflammatory bowel disease: findings from two nationally representative Canadian surveys. Inflamm Bowel Dis. 2006; 12:697-707. [PubMed: 16917224]

7. Schoevers RA, Beekman AT, Deeg DJ, Geerlings MI, Jonker C, Van Tilburg W. Risk factors for depression in later life; results of a prospective community based study (AMSTEL). J Affect Disord. 2000; 59:127-37. [PubMed: 10837881]

8. Reynolds CF 3rd, Cuijpers P, Patel V, Cohen A, Dias A, Chowdhary N, Okereke OI, Dew MA, Anderson SJ, Mazumdar S, Lotrich F, Albert SM. Early intervention to reduce the global health and economic burden of major depression in older adults. Annu Rev Public Health. 2012; 33:123-35. [PubMed: 22429161]

9. Long MD, Kappelman MD, Martin CF, Lewis JD, Mayer L, Kinneer PM, Sandler RS. Development of an internet-based cohort of patients with inflammatory bowel diseases (CCFA Partners): methodology and initial results. Inflamm Bowel Dis. 2012; 18:2099-106. [PubMed: 22287300]

10. Thia K, Faubion WA Jr. Loftus EV Jr. Persson T, Persson A, Sandborn WJ. Short CDAI: development and validation of a shortened and simplified Crohn's disease activity index. Inflamm Bowel Dis. 2011; 17:105-11. [PubMed: 20629100]

11. Walmsley RS, Ayres RC, Pounder RE, Allan RN. A simple clinical colitis activity index. Gut. 1998; 43:29-32. [PubMed: 9771402]

12. Clara I, Lix LM, Walker JR, Graff LA, Miller N, Rogala L, Rawsthorne P, Bernstein CN. The Manitoba IBD Index: evidence for a new and simple indicator of IBD activity. Am J Gastroenterol. 2009; 104:1754-63. [PubMed: 19455122]

13. Irvine EJ, Zhou Q, Thompson AK. The Short Inflammatory Bowel Disease Questionnaire: a quality of life instrument for community physicians managing inflammatory bowel disease. CCRPT Investigators. Canadian Crohn's Relapse Prevention Trial. Am J Gastroenterol. 1996; 91:1571-8. [PubMed: 8759664]

14. Morisky DE, Ang A, Krousel-Wood M, Ward HJ. Predictive validity of a medication adherence measure in an outpatient setting. J Clin Hypertens (Greenwich). 2008; 10:348-54. [PubMed: 18453793]

15. Godin G, Shephard RJ. A simple method to assess exercise behavior in the community. Can J Appl Sport Sci. 1985; 10:141-6. [PubMed: 4053261]

16. Yesavage JA, Brink TL, Rose TL, Lum O, Huang V, Adey M, Leirer VO. Development and validation of a geriatric depression screening scale: a preliminary report. J Psychiatr Res. 1982; 17:37-49. [PubMed: 7183759]

17. Almeida OP, Almeida SA. Short versions of the geriatric depression scale: a study of their validity for the diagnosis of a major depressive episode according to ICD-10 and DSM-IV. Int J Geriatr Psychiatry. 1999; 14:858-65. [PubMed: 10521885]

18. Murray CJ, Lopez AD. Alternative projections of mortality and disability by cause 1990-2020: Global Burden of Disease Study. Lancet. 1997; 349:1498-504. [PubMed: 9167458]

19. Regan CO, Kearney PM, Savva GM, Cronin H, Kenny RA. Age and sex differences in prevalence and clinical correlates of depression: first results from the Irish Longitudinal Study on Ageing. Int J Geriatr Psychiatry. 2013

20. Forlani C, Morri M, Ferrari B, Dalmonte E, Menchetti M, De Ronchi D, Atti AR. Prevalence and Gender Differences in Late-Life Depression: A Population-Based Study. Am J Geriatr Psychiatry. 2013

21. Beekman AT, Deeg DJ, van Tilburg T, Smit JH, Hooijer C, van Tilburg W. Major and minor depression in later life: a study of prevalence and risk factors. J Affect Disord. 1995; 36:65-75. [PubMed: 8988267] 
22. Guthrie E, Jackson J, Shaffer J, Thompson D, Tomenson B, Creed F. Psychological disorder and severity of inflammatory bowel disease predict health-related quality of life in ulcerative colitis and Crohn's disease. Am J Gastroenterol. 2002; 97:1994-9. [PubMed: 12190166]

23. Mittermaier C, Dejaco C, Waldhoer T, Oefferlbauer-Ernst A, Miehsler W, Beier M, Tillinger W, Gangl A, Moser G. Impact of depressive mood on relapse in patients with inflammatory bowel disease: a prospective 18-month follow-up study. Psychosom Med. 2004; 66:79-84. [PubMed: 14747641]

24. Szigethy E, Levy-Warren A, Whitton S, Bousvaros A, Gauvreau K, Leichtner AM, Beardslee WR. Depressive symptoms and inflammatory bowel disease in children and adolescents: a crosssectional study. J Pediatr Gastroenterol Nutr. 2004; 39:395-403. [PubMed: 15448431]

25. Gallagher R, Zelestis E, Hollams D, Denney-Wilson E, Kirkness A. Impact of the Healthy Eating and Exercise Lifestyle Programme on depressive symptoms in overweight people with heart disease and diabetes. Eur J Prev Cardiol. 2013

26. Stanton R, Reaburn P. Exercise and the treatment of depression: A review of the exercise program variables. J Sci Med Sport. 2013

27. Danielsson L, Noras AM, Waern M, Carlsson J. Exercise in the treatment of major depression: A systematic review grading the quality of evidence. Physiother Theory Pract. 2013

28. Perez-Zepeda MU, Arango-Lopera VE, Wagner FA, Gallo JJ, Sanchez-Garcia S, Juarez-Cedillo T, Garcia-Pena C. Factors associated with help-seeking behaviors in Mexican older individuals with depressive symptoms: a cross-sectional study. Int J Geriatr Psychiatry. 2013

29. Grenard JL, Munjas BA, Adams JL, Suttorp M, Maglione M, McGlynn EA, Gellad WF. Depression and medication adherence in the treatment of chronic diseases in the United States: a meta-analysis. J Gen Intern Med. 2011; 26:1175-82. [PubMed: 21533823]

30. Mackner LM, Greenley RN, Szigethy E, Herzer M, Deer K, Hommel KA. Psychosocial Issues in Pediatric Inflammatory Bowel Disease: A Clinical Report of the North American Society for Pediatric Gastroenterology, Hepatology and Nutrition. J Pediatr Gastroenterol Nutr. 2013 


\section{Geriatric Depression Scale: Short Form}

Choose the best answer for how you have felt over the past week:

1. Are you basically satisfied with your life? YES / NO

2. Have you dropped many of your activities and interests? YES / NO

3. Do you feel that your life is empty? YES / NO

4. Do you often get bored? YES / NO

5. Are you in good spirits most of the time? YES / NO

6. Are you afraid that something bad is going to happen to you? YES / NO

7. Do you feel happy most of the time? YES / NO

8. Do you often feel helpless? YES / NO

9. Do you prefer to stay at home, rather than going out and doing new things? YES / NO

10. Do you feel you have more problems with memory than most? YES / NO

11. Do you think it is wonderful to be alive now? YES / NO

12. Do you feel pretty worthless the way you are now? YES / NO

13. Do you feel full of energy? YES / NO

14. Do you feel that your situation is hopeless? YES / NO

15. Do you think that most people are better off than you are? YES / NO

Answers in bold indicate depression.

Figure 1. Short Geriatric Depression Scale

A score of $\geq 5$ indicates depression 


\section{Panel A: Crohn's disease}

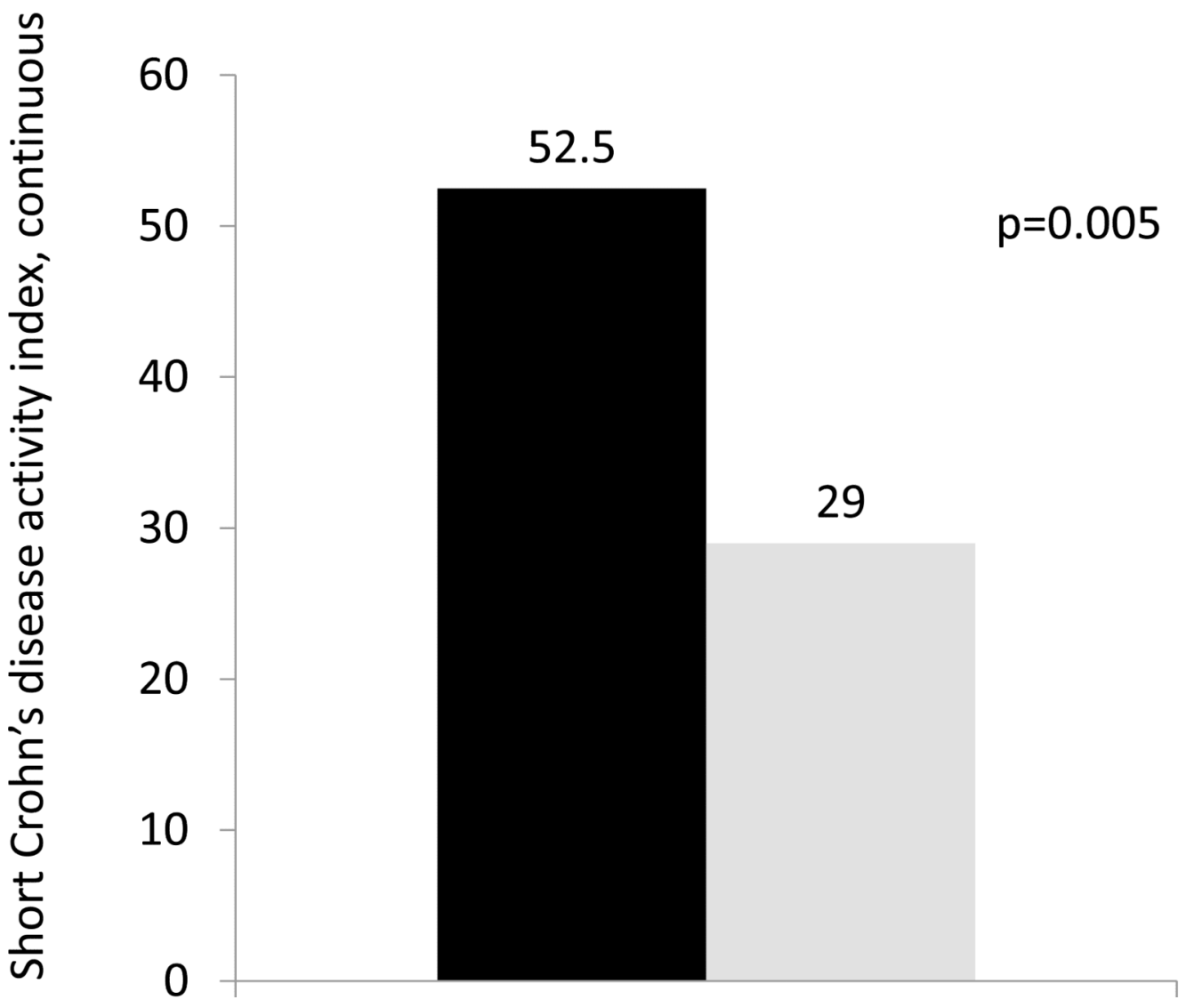

- Depression

No Depression 


\section{Panel B: Ulcerative colitis}

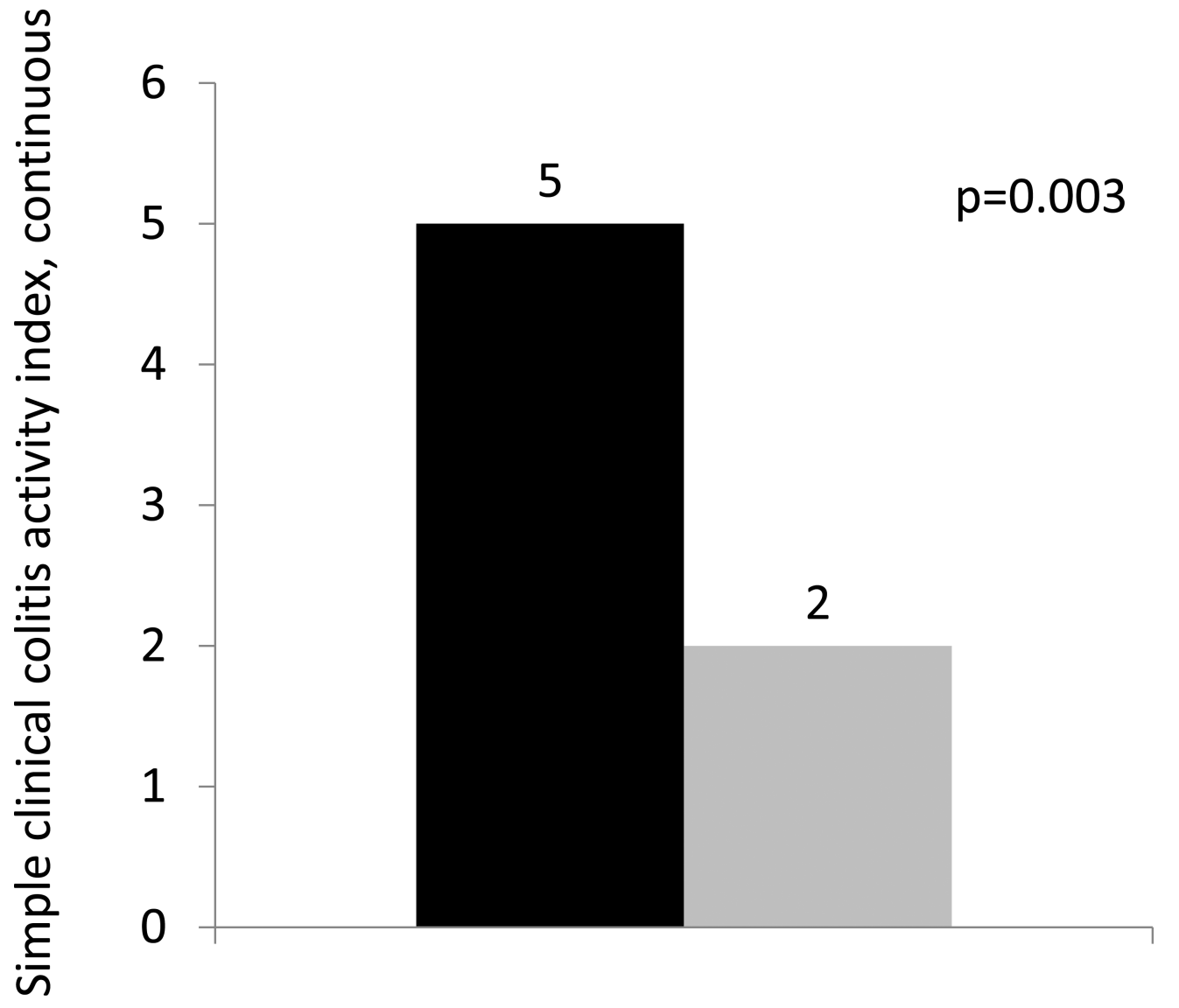

- Depression

No Depression 


\section{Panel C: Inflammatory Bowel Disease}

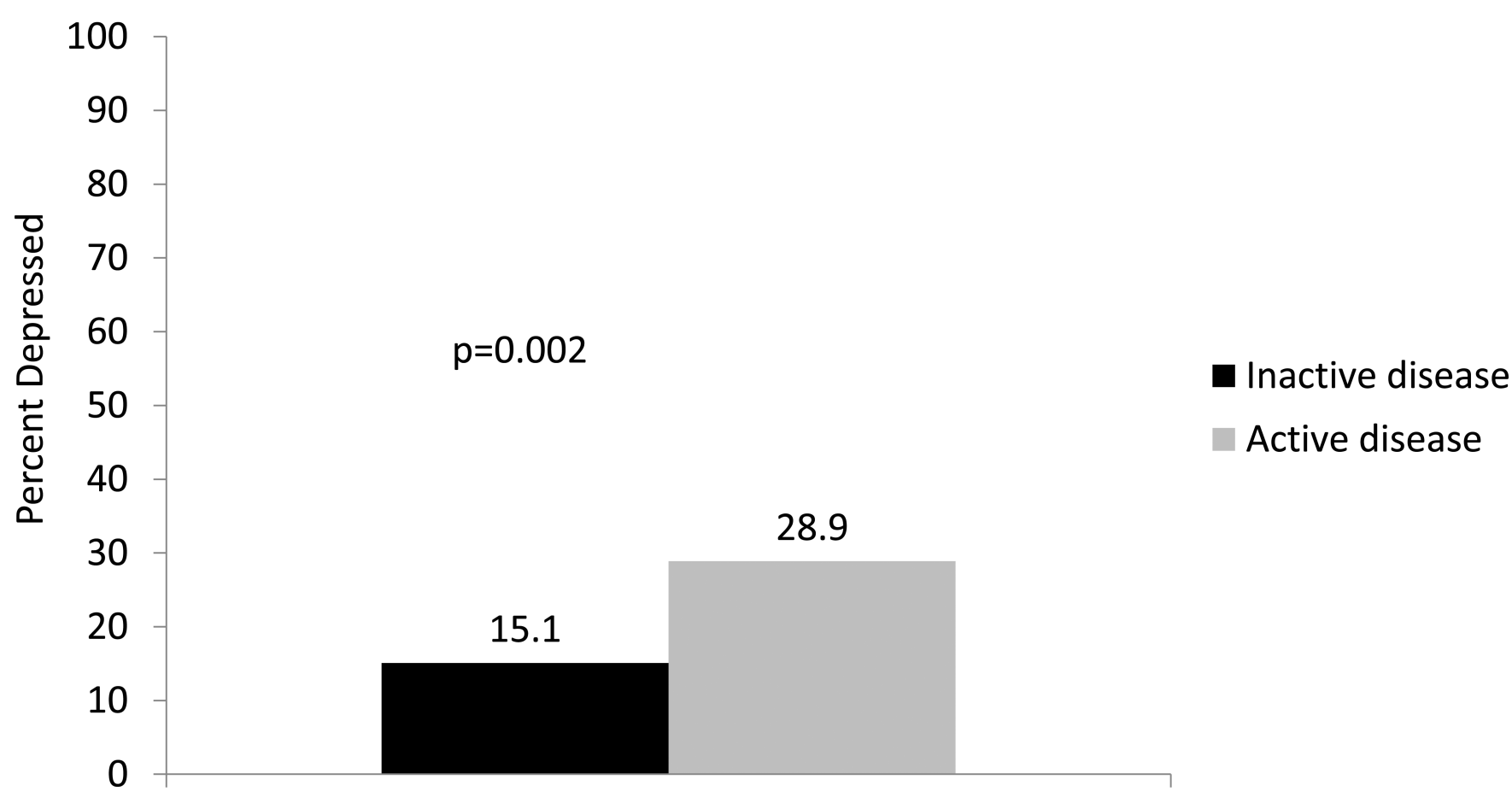

Figure 2. Disease activity measurements by depression status in the elderly IBD population within CCFA Partners cohort

a. Crohn's disease*

b. Ulcerative colitis**

c. IBD population, overall percent with depression by disease status over the past 6 months ${ }^{\wedge}$ *Disease activity measured by the short Crohn's disease activity index (sCDAI)

**Disease activity measured by the simple clinical colitis activity index (SCCAI)

${ }^{\wedge}$ Disease activity measured by the Manitoba inflammatory bowel disease index (MIBDI) 
Table 1

Baseline characteristics of the elderly inflammatory bowel disease population in CCFA Partners, by depression status

\begin{tabular}{|c|c|c|c|c|c|}
\hline \multirow[t]{2}{*}{ Characteristic } & \multicolumn{2}{|c|}{ Depression $(n=81)$} & \multicolumn{2}{|c|}{ No Depression $(n=278)$} & \multirow{2}{*}{ p value } \\
\hline & $\mathbf{n}$ & mean (sd), median (IQR) or \% & $\mathbf{n}$ & mean (sd), median (IQR) or \% & \\
\hline Age (years) & 79 & $70(5.3)$ & 274 & $70(4.5)$ & 0.89 \\
\hline Gender (\% female) & 49 & 60.5 & 174 & 63.0 & 0.68 \\
\hline \multicolumn{6}{|l|}{ Type of IBD } \\
\hline Crohn's disease & 54 & 66.7 & 170 & 61.4 & 0.39 \\
\hline Ulcerative/indeterminate colitis & 27 & 33.3 & 107 & 38.6 & \\
\hline Duration of disease (years) & 79 & $24.2(16.8)$ & 269 & $25.8(17.8)$ & 0.50 \\
\hline Ostomy (\% yes) & 11 & 13.6 & 30 & 10.8 & 0.49 \\
\hline Surgery in the past 6 months (\% yes) & 2 & 2.5 & 7 & 2.6 & 0.99 \\
\hline Primary care visit in past 6 months (\% yes) & 74 & 96.1 & 240 & 89.2 & 0.08 \\
\hline \multicolumn{6}{|l|}{ Medications } \\
\hline 5-ASA & 38 & 47.5 & 150 & 54.4 & 0.28 \\
\hline Corticosteroids & 20 & 25.0 & 32 & 11.6 & $<0.01$ \\
\hline Immunomodulators & 20 & 25.0 & 61 & 22.1 & 0.59 \\
\hline Biologic anti-TNF & 18 & 22.5 & 50 & 18.1 & 0.38 \\
\hline \multicolumn{6}{|l|}{ Education } \\
\hline High school or less & 16 & 21.3 & 21 & 8.1 & 0.001 \\
\hline College + & 59 & 78.7 & 238 & 91.9 & \\
\hline \multicolumn{6}{|l|}{ Disease activity } \\
\hline $\operatorname{sCDAI}^{* *}$ & 46 & $52.5(29-134)$ & 150 & $29(10-83)$ & 0.005 \\
\hline $\mathrm{SCCAI}^{\#}$ & 27 & $5(1-6)$ & 107 & $2(1-3)$ & 0.003 \\
\hline Quality of life (SIBDQ) & 78 & $4.6(3.8-5.2)$ & 269 & $5.7(5.1-6.2)$ & $<0.001$ \\
\hline Exercise $^{+}$ & 79 & $15(3-30)$ & 275 & $21.0(9-37)$ & $<0.001$ \\
\hline \multicolumn{6}{|l|}{ \%Morisky medication adherence scale } \\
\hline \multicolumn{6}{|c|}{ * by wilcoxon rank sum, $\mathrm{t}$-test, chi square or fisher's exact as appropriate } \\
\hline \multicolumn{6}{|l|}{ ** short Crohn's disease activity index } \\
\hline \multicolumn{6}{|l|}{${ }^{\#}$ simple clinical colitis activity index } \\
\hline ^short inflammatory bowel disease questionn & & & & & \\
\hline
\end{tabular}


Table 2

Medication adherence in elderly patients in the CCFA Partners cohort, among those taking at least one medication for inflammatory bowel disease $(n=240)$

\begin{tabular}{|c|c|c|c|c|c|}
\hline \multirow{2}{*}{ Medication adherence ${ }^{*}$} & \multicolumn{2}{|c|}{ Depression } & \multicolumn{2}{|c|}{ No depression } & \multirow{2}{*}{ p value ${ }^{* * *}$} \\
\hline & $\mathbf{n}$ & $\%$ & $\mathbf{n}$ & $\%$ & \\
\hline Low $(<6)$ & 15 & 28.9 & 36 & 19.7 & 0.01 \\
\hline Medium $(6-<8)$ & 22 & 42.3 & 51 & 27.9 & \\
\hline High (8) & 15 & 28.9 & 96 & 52.5 & \\
\hline \multicolumn{6}{|c|}{ Morisky medication adherence scale } \\
\hline
\end{tabular}

